\title{
Intracerebral hemorrhage in critically ill patients admitted in a general ICU of a hospital without neurosurgical service
}

\author{
A Estella*, T Rico Armenteros, M Jaen Franco, P Guijo, L Fernández Ruiz, M Recuerda Nuñez \\ From ESICM LIVES 2015 \\ Berlin, Germany. 3-7 October 2015
}

\section{Introduction}

The type of ICU that admits patients with an intracerebral hemorrhage ( $\mathrm{ICH})$ varies considerably; some authors suggest that for critically ill patients with $\mathrm{ICH}$ admission in a neuro-ICU is associated with reduced mortality. Coordination with the reference centers is still necessary.

\section{Objectives}

The aim of this study was to describe the clinical profile of patients with intracranial hemorrhage admitted to a general ICU and to analyze which patients are transferred to a hospital with neurosurgery department.

\section{Methods}

Descriptive study in an ICU of a community hospital. Time of study was 20 months. Consecutive critically ill patients with ICH admitted in ICU were included. The variables analyzed were age, sex, medical history, APACHE II and Glasgow Coma Scores collected at the time of ICU admission, transfers to reference hospital and ICU length of stay.The data were analyzed using SPSS version 18 for Windows.

\section{Results}

50 patients, 35 men and 15 women were included. Mean age was $64.12 \pm 6.2$ years. Most of patients had medical history of hypertension, $66.7 \%$. A third of ICH patients were treated with antiplatelet agents and $16.7 \%$ were anticoagulated. $82 \%$ required mechanical ventilation and $54 \%$ were treated at admission with intravenous antihypertensive drugs. Maximum length of ICU stay was 27 days and $12 \%$ of patients required tracheotomy.
Table 1

\begin{tabular}{lll}
\hline & $\begin{array}{l}\text { Transfer to Neuro- } \\
\text { ICU } \mathbf{n : 1 2}\end{array}$ & $\begin{array}{l}\text { General ICU } \\
\mathbf{n : 3 8}\end{array}$ \\
\hline Age & $52.6 \pm 9.7$ & $67.8 \pm 11.2$ \\
\hline Apache II at ICU admission & $12.4 \pm 6.4$ & $23.5 \pm 7.2$ \\
\hline $\begin{array}{l}\text { Glasgow coma score at ICU } \\
\text { admission }\end{array}$ & $7.5 \pm 4.5$ & $6.4 \pm 3.7$ \\
\hline Antiplatelet agents & $8.3 \%$ & $36.8 \%$ \\
\hline Anticoagulation therapy & $8.3 \%$ & $18.4 \%$ \\
\hline ICU lenght of stay (days) & $2.2 \pm 3.7$ & $6 \pm 6.39$ \\
\hline
\end{tabular}

[Clinical characteristics ICH patients]

24 patients were accepted to transfer to a neuro-ICU at the reference hospital. We distinguish two subgroups according patients transferred to the reference hospital (24\%), table 1 shows differences observed.

\section{Conclusions}

The predominant clinical profile was hypertensive male with requirements of mechanical ventilation and antihypertensive iv drugs at admission.

Age, GCS and Apache II at admission were significantly lower in patients accepted to transfer to the reference hospital for neurosurgical evaluation.

Published: 1 October 2015

doi:10.1186/2197-425X-3-S1-A982

Cite this article as: Estella et al:: Intracerebral hemorrhage in critically ill patients admitted in a general ICU of a hospital without neurosurgical service. Intensive Care Medicine Experimental 2015 3(Suppl 1):A982. 